this programme. In the few cases where radiology was performed before direct inspection there was a poor correlation between its interpretation and laryngoscopic diagnosis. Similarly, we found that history and clinical examination were unreliable in distinguishing between epiglottitis and severe viral croup. Hence direct visualisation is important in children with severe acute stridor and requires the emergency availability of experienced staff in any centre admitting such patients.

\author{
References \\ ${ }^{1}$ Porter FN. Neck radiographs in croup syndrome. Arch Dis \\ Child 1985;60:82-3.
}
I A Auchterlonie AND B Benjamin University of Aberdeen, Aberdeen $A B 92 Z D$

\section{Exercise test for growth hormone deficiency}

Sir,

I agree with many of Charles Brook's ${ }^{1}$ comments on growth hormone tests but do not believe that in a busy district general hospital screening for growth hormone deficiency with the strenuous exercise test as described by $\mathrm{Nicol}^{2}$ and Lazaro ${ }^{3}$ would be readily available, nor do I think that hospital admission for venous samples during deep sleep under electroencephalographic monitoring is an acceptable alternative. I am in no doubt that the kindest and most efficient screening test for growth hormone deficiency is referral to a growth centre. If this is done then generally no investigation is necessary and the half hour consultation will quickly allay the family's concern.

In my growth clinic in Bristol I see 150 to 200 short children a year and in the vast majority the diagnosis is self evident without any investigation. In the very few where growth hormone deficiency is a possibility I prefer to do a definitive test (sequential insulin and arginine) than a screening test. We do about 12 tests a year and diagnose eight to 10 cases of growth hormone deficiency annually which is no different from other regions of comparable size.

\section{References}

${ }^{1}$ Brook CDG. Exercise test for growth hormone deficiency and Treadmill exercise test in short children. (Commentary) Arch Dis Child 1984;59:1181-2.

2 Nicol AG, Smail PJ, Forsyth CC. Exercise test for growth hormone deficiency. Arch Dis Child 1984;59:1177-8.

3 San Lazaro C de, Parkin JM, Turner SJ. Treadmill exercise test in short children. Arch Dis Child 1984;59:1179-81.

D C L SAvage Royal Hospital for Sick Children, Bristol BS2 8BJ

\section{Inhaled non-radio-opaque foreign bodies}

Sir,

Most foreign bodies inhaled by children consist of parts of toys and organic materials (often foodstuffs such as peanuts) and these are unlikely to show up radiologically. Furthermore with laryngotracheal foreign bodies the radiographs of neck and chest are often normal but with bronchial foreign bodies obstructive emphysema may be present.

Recently, we have seen two infants presenting with croup syndrome who were later found to have laryngotracheal foreign bodies. Both infants had inhaled pieces of toys that did not show up radiologically. One infant had cardiorespiratory arrest and a piece of Lego was found in the trachea at necropsy. In the other infant there was a delay in making the correct diagnosis and therefore delay in removal of an Action Man from the larynx.

I suspect that paediatricians in other parts of the globe may have also encountered similar diagnostic dilemmas. Should we not therefore ask the toy manufacturers to consider seriously adding some radio-opaque substance to the toy material so that an earlier diagnosis and treatment can be instituted?

$$
\begin{array}{r}
\text { K M GoEL } \\
\text { Royal Hospital for Sick Children, } \\
\text { Glasgow G3 8SJ }
\end{array}
$$

